\title{
Detection of thyroid peroxidase mRNA in peripheral blood of patients with malignant and benign thyroid diseases
}

\author{
S J Roddiger, J Bojunga ${ }^{1}$, V Klee ${ }^{1}$, M Stanisch ${ }^{1}$, H Renneberg ${ }^{2}$, E Lindhorst ${ }^{3}$, \\ K H Usadel ${ }^{1}$, K Kusterer ${ }^{1}$, P M Schumm-Draeger ${ }^{1}$ and $\mathbf{R}$ Kurek
}

Department of Radiation Oncology, Academic Hospital, Starkenburgring 66, 63069 Offenbach, Germany

${ }^{1}$ Department of Endocrinolgy, J W Goethe-University, Theodor-Stern-Kai 7, 60599 Frankfurt am Main, Germany

${ }^{2}$ Department of Anatomy and Cell Biology, Philipps-University, 35033 Marburg, Germany

${ }^{3}$ Department of Surgery, J W Goethe-University, Theodor-Stern-Kai 7, 60599 Frankfurt am Main, Germany

(Requests for offprints should be addressed to R Kurek; Email: rkurek@gmx.de)

(H Renneberg is currently at Fred Hutchinson Cancer Research Center, Seattle, WA, USA)

\begin{abstract}
The aim of this study was to evaluate thyroid peroxidase (TPO) mRNA expression in peripheral blood of patients with benign and malignant thyroid disease. Included were 120 thyroid cancer patients, 85 patients with goitre or Graves' disease (GD) and 54 healthy volunteers. TPO mRNA expression was analysed in peripheral blood by nested RT-PCR. In cancer patients, RT-PCR results were compared with staging, grading and serum thyroglobulin (TG) measurement. TPO transcripts were detected in 7/10 $(70 \%)$ patients with known metastases of thyroid cancer and in 39 of $110(36 \%)$ patients without metastases $(P<0.05)$, in $15 / 44(34 \%)$ patients with goitre, in $17 / 41(41 \%)$ cases with GD and in $4 / 54$ $(7.4 \%)$ subjects in the control group $(P<0.05$, controls vs all patients with thyroid disease). Among cancer patients without metastatic disease, RT-PCR results correlated positively with lymph node status $(P=0.05)$, grading $(P=0.01)$ and elevated serum thyroglobulin levels $(P=0.03)$. This is the largest study investigating the use of the TPO-RT-PCR assay. Positivity in TPO-RT-PCR correlates significantly with metastatic disease in cancer patients and with the presence of thyroid disease in general. To date, TPO-RT-PCR cannot substitute for standard techniques in the diagnosis of local recurrence or metastatic spread in thyroid cancer patients. However, as results of TPO-RT-PCR correlate significantly with lymph node status, grading and serum TG measurements in patients with non-metastatic disease, TPO seems to be an interesting molecular marker to look at in follow-up studies.
\end{abstract}

Journal of Molecular Endocrinology (2002) 29, 287-295

\section{Introduction}

Follicular and papillary thyroid carcinomas are the most common malignancies arising in the thyroid gland. Postoperative status, distant metastases and nodal involvement were found to be significant prognostic factors among other features such as age at diagnosis and pathological type (Simpson et al. 1987, Haber 1998). Monitoring for recurrence includes ultrasound of the neck, measurement of serum thyroglobulin and radioiodine scanning. One disadvantage of these surveillance methods - with the exception of ultrasound - is the fact that they need stimulation of thyroid tissue by thyrotrophin (TSH) either after withdrawal of thyroid hormone therapy or by injection of recombinant TSH. Both contain the potential of stimulating tumour growth (Ladenson et al. 1997). Antibodies against thyroglobulin, which are detectable in up to $40 \%$ of patients' sera, may lead to false negative results in thyroglobulin testing (Ligabue et al. 1993, Spencer et al. 1998).

In addition, the question still remains of what to do in cases of positive serum thyroglobulin and negative findings in the radioiodine scan. Pineda et al. (1995) treated those patients with 150-300 
$\mathrm{mCi}{ }^{131} \mathrm{I}$ and found undiagnosed local recurrence or metastases in the majority of patients by post therapy whole body scans. Furthermore, the serum thyroglobulin (TG) levels fell to $5 \mathrm{ng} / \mathrm{ml}$ or less in about $50 \%$ of the patients and the authors were able to show a conversion to negative whole body scans in some of their patients (Pineda et al. 1995). In contrast to this study, Pacini et al. (2001) found further ${ }^{131}$ I treatment of patients with elevated TG levels and negative radioiodine scan useful only in cases with pulmonary metastases in post therapy scans. As the optimal diagnostic and treatment schedules for those patients have not yet been found, other diagnostic methods such as detection of molecular markers are under investigation.

Since 1987, reverse transcriptase (RT)-PCR has been used in detecting circulating cells of solid tumours by amplification of organ-specific mRNAs in the patients' peripheral blood stream. Examples of known molecular markers are HER2/neu for the detection of breast cancer (Wasserman et al. 1999), prostate specific antigen, prostate specific membrane antigen and hK2 for prostate cancer (Corey \& Corey 1998, Renneberg et al. 1999) and $\alpha$-feto-protein (AFP) for hepatoma (Komeda et al. 1995). In patients with thyroid carcinoma, mRNAs of thyroglobulin, thyroid peroxidase (TPO), RET/ PTC1 and NIS have been investigated as potential molecular markers (Ditkoff et al. 1996, Arturi et al. 1997, Aust et al. 1998, Ringel et al. 1998, 1999, Tallini et al. 1998, Wingo et al. 1999, Biscolla et al. 2000, Bojunga et al. 2000, Bellantone et al. 2001, Fenton et al. 2001, Takano et al. 2001, Savagner et al. 2002).

While thyroglobulin mRNA transcripts in peripheral blood have been studied by several authors, only one paper has been published using thyroid peroxidase as a possible molecular marker (Tallini et al. 1998).

TPO is a membrane-bound protein catalysing iodide oxidation, iodination of tyrosine residues and generation of triiodothyronine and thyroxine. In autoimmune thyroid disease anti-TPO antibodies are found in the sera of patients. The TPO gene includes 17 exons, and different splice variants of approximately $3 \mathrm{~kb}$ mRNA have been reported (Kimura et al. 1989).

We established a molecular assay for the detection of TPO mRNA in whole blood samples based on a nested RT-PCR protocol. In this study, we examined the largest group of patients with malignant as well as benign thyroid disease and the largest group of control patients to date. In cancer patients, results were correlated with postoperative pathological staging and grading. In addition, results were compared with serum TG measurements.

\section{Materials and methods}

\section{Patients}

After approval by the institutional review board, 120 patients with a history of thyroid cancer (110 without current metastases, 10 with metastatic disease) were enrolled in our study. Median age at initial diagnosis was 41 years (range 23-86 years). Thirty-nine $(32.5 \%)$ of the patients were male, 81 $(67 \cdot 5 \%)$ were female. All patients had been treated with total thyroidectomy. Diagnosis of cancer was based on histological examination of surgical specimens by the pathology department. In 7 patients, diagnosis of cancer was made after partial resection of the thyroid, which was preoperatively thought to be enlarged because of iodine deficiency. In those patients, total thyroidectomy was performed within the next two to three days. After surgery one cycle of radioiodine $\left({ }^{131} \mathrm{I}\right)$ was given. The mean dose was $3 \cdot 7$ Gigabecquerel $(\mathrm{GBq})$, the maximum dose was $7 \cdot 4 \mathrm{GBq}$. Five to seven days after completion of radioiodine therapy, patients were monitored for remaining thyroid tissue and metastases using a post-therapy ${ }^{131} \mathrm{I}$ scan. All patients underwent a diagnostic whole body scan (mean dose: $740 \mathrm{MBq}$ ) three months after the end of the primary therapy. In cases with remaining thyroid tissue, one more cycle of radioiodine was given. All patients were taking thyroxine $\left(\mathrm{T}_{4}\right)$ to completely suppress TSH production. Over the first follow-up-period of 5 years patients were examined every 6 months by thyroid ultrasound, and TG levels in whole blood were measured. A bone-scan using $\mathrm{Tc}^{99 \mathrm{~m}}$ (555 MBq) was carried out every year. In 106 of 110 patients without metastatic disease the data relating to tumour size (T) was accessible. In 89 of 110 patients the data relating to lymph node involvement $(\mathrm{N})$ was accessible. For TNM classification the version of Sobin \& Fleming (1997) was used. Grading was carried out in 47 of 110 patients based upon the system of Akslen (1993). Serum thyroglobulin measurement was carried out in all 
Table 1 Results of TPO-RT-PCR for all thyroid cancer patients and for MO patients according to histological typing, TNM stages and grading

\begin{tabular}{|c|c|c|}
\hline & $\begin{array}{l}\text { RT-PCR+/patients } \\
\text { with papillary } \\
\text { thyroid CA }\end{array}$ & $\begin{array}{l}\text { RT-PCR+/patients } \\
\text { with follicular } \\
\text { thyroid CA }\end{array}$ \\
\hline M0 & 29/88 (33\%) & $10 / 22(45 \cdot 5 \%)$ \\
\hline M1 & $3 / 4(75 \%)$ & $4 / 6(66 \cdot 7 \%)$ \\
\hline \multicolumn{3}{|c|}{ M0 patients } \\
\hline T1 & $15 / 39(38.5 \%)$ & $1 / 1(100 \%)$ \\
\hline T2 & $9 / 29(31 \%)$ & $4 / 10(40 \%)$ \\
\hline T3 & $3 / 8(37.5 \%)$ & 3/8 (37.5\%) \\
\hline T4 & $1 / 8(12.5 \%)$ & $1 / 3(33.3 \%)$ \\
\hline No & $12 / 50(24 \%)$ & $7 / 17(41 \%)$ \\
\hline $\mathrm{N}+$ & $8 / 19(42 \%)$ & $2 / 3(66 \%)$ \\
\hline G1 & $9 / 18(50 \%)$ & $1 / 5(20 \%)$ \\
\hline G2 & $7 / 17(41.2 \%)$ & $1 / 3(33.3 \%)$ \\
\hline G3 & $1 / 1(100 \%)$ & $2 / 3(66.7 \%)$ \\
\hline
\end{tabular}

CA, cancer.

120 cancer patients at the same time as the blood sample for the RT-PCR assay was taken. Distribution of the TNM stages and grading of the cancer patients as well as histological typing are listed in Table 1 together with the results.

Also included in our study were 41 patients with Graves' disease whose mean age was 30 years (range 22-79 years); 8 (19.5\%) patients were male, $33(80 \cdot 5 \%)$ were female. Furthermore, we included 44 patients with euthyroid goitre due to iodine deficiency. Their mean age was 45 years (range 26-83 years), $10(22 \cdot 7 \%)$ patients were male, 34 $(77 \cdot 3 \%)$ were female. Fifty-four control subjects without evidence or history of thyroid disease were also enrolled. The median age was 38 years (range 23-79 years), $20(37 \%)$ were male, $34(63 \%)$ were female. Diagnosis of autoimmune and nonautoimmune thyroid disease was based on typical clinical findings, ultrasound examination, laboratory criteria (TSH, free (f) triiodothyronine $\left(\mathrm{fT}_{3}\right.$ ), $\mathrm{fT}_{4}$ ) and the presence of autoantibodies against the thyrotrophin receptor in Graves' disease. All patients were followed at the endocrine outpatient clinic of Johann Wolfgang Goethe-University Hospital.

\section{Blood samples and RNA extraction}

Venous blood $(9 \mathrm{ml})$ was taken from each patient using EDTA-coated tubes and cooled down to
$4{ }^{\circ} \mathrm{C}$ immediately. A Percoll gradient (Pharmacia, Uppsala, Sweden) was used to isolate nucleated cells within $2 \mathrm{~h}$ after withdrawal of blood. The cell suspension was washed once in $0.9 \%$ sodium chloride and the remaining erythrocytes were lysed. Total cellular RNA was extracted as described above using an RNeasy blood kit (Quiagen, Hilden, Germany). Serum for thyroglobulin measurements was obtained using the supernatant after centrifugation of the Percoll gradient.

\section{Oligonucleotide primers}

Primers were custom designed by MWG-Biotech (Ebersberg, Germany) according to the human thyroid peroxidase cDNA sequence reported by Kimura et al. (1989) (Gene Bank accession number M25702 J02856). The outer primer pair corresponds to sequences on exons 2 and 5 respectively, the nested primer pair binds to sequences on exons 3 and 5. The ladder exons are separated by 2 large introns containing, together, more than $4 \mathrm{~kb}$. To assess the intactness of amplifiable RNA, two intron-spanning glyceraldehyde 3-phosphate dehydrogenase (GAPDH) primers that generate a $300 \mathrm{bp}$ fragment (Gene Bank accession number M33197) were used. Local alignment was performed using BLAST search (http://www.ncbi. nlm.nih.gov). Primer sequences are listed in Table 2 .

\section{Reverse transcriptase-polymerase chain reaction}

Approximately $2 \mu \mathrm{g}$ total RNA were reverse transcribed in a final volume of $20 \mu$ containing $4 \mu \mathrm{l} 5 \times$ buffer $(250 \mathrm{mM}$ Tris-HCl pH 7.5, $375 \mathrm{mM} \mathrm{KCl}, 15 \mathrm{mM} \mathrm{MgCl} 2,50 \mathrm{mM}$ dithiothreitol (DTT)), 20 units recombinant RNase inhibitor (Promega, Madison, WI, USA), 0.5 mM dNTP, $2 \cdot 5 \mu \mathrm{M}$ oligo dT and 200 units RNAse $\mathrm{H}$ minus M-MLV reverse transcriptase (Promega). The following PCR was performed in a total volume of $50 \mu \mathrm{l}$ containing $2 \mu \mathrm{l}$ of the RT-solution, $5 \mu \mathrm{l}$ $10 \times$ reaction buffer $(200 \mathrm{mM}$ Tris $-\mathrm{HCl}$ pH $8 \cdot 4$, $500 \mathrm{mM} \mathrm{KCl}$ ), $0 \cdot 1 \mu \mathrm{M}$ forward and reverse primer, $0 \cdot 2 \mu \mathrm{M}$ of each dNTP, $2 \cdot 5$ units Taq-DNA polymerase (PAN Systems gmbh, Aidenbach, Germany) and $1.5 \mathrm{mM} \mathrm{MgCl}_{2}$ (Life Technology, Paisley, UK) using a tube-controlled DNA thermal cycler (AGS-Hybaid, Heidelberg, Germany). 
Table 2 Overview of primer sequences

\section{Sequence}

\author{
Primer \\ Thyroid peroxidase \\ Sense \\ Antisense \\ Thyroid peroxidase \\ Sense, nested \\ Antisense, nested \\ GAPDH \\ Sense \\ Antisense
}

5'-GCC TTC TTC CCC TTC ATC TC-3'
5'-GTT GTT GCA AGC TCC TGT GA-3'
5'-GTG TCT CTA GCG TCT TGG AGG A-3'
5'-ACA TCC AGA CAT GTT TGC AAT G-3'
5'-CGTCTTCACCACCATGGAGA-3'
5'-CGGCCATCACGCCACAGTTT-3'

Samples were denaturated for $3 \mathrm{~min}$ at $94^{\circ} \mathrm{C}$ followed by 35 cycles of $45 \mathrm{~s}$ at $94{ }^{\circ} \mathrm{C}, 60 \mathrm{~s}$ at $54^{\circ} \mathrm{C}$, $60 \mathrm{~s}$ at $72^{\circ} \mathrm{C}$, followed by an additional $10 \mathrm{~min}$ at $72{ }^{\circ} \mathrm{C}$. For nested PGR, $1 \mu \mathrm{l}$ of the first PGR instead of $2 \mu \mathrm{l}$ was added to the PGR cup under the same protocol as described above. The number of cycles was reduced to 20 . In each experiment water served as a negative control and cDNA from thyroid tissue - processed as described below served as a positive control.

\section{Analysis of amplified thyroid peroxidase cDNA}

Ten microlitres PGR product were mixed with $2 \mu \mathrm{l}$ $6 \times$ loading dye (MBI Fermentas, St Leon-Rot, Germany) and run for $60 \mathrm{~min}$ on a $1.5 \%$ agarose gel in TBE buffer $(0 \cdot 1 \mathrm{M}$ Tris pH $8 \cdot 4,90 \mathrm{mM}$ boric acid, $1 \mathrm{mM}$ EDTA). The gel was stained with $2 \%$ ethidium bromide and the amplicons were visualized on a UV-transilluminator. Samples were subjected to Southern blot hybridization to confirm product identitiy. Representative amplicons were commercially sequenced (SeqLab, Göttingen, Germany).

\section{Thyroid peroxidase RT-PCR assay sensitivity}

RT-PCR assay sensitivity was determined by the dilution of thyroid cells from surgery for goitre with peripheral blood mononuclear cells (PBMC) of a negative control patient thus simulating shedding of thyroid-derived tumour cells in the peripheral blood stream. The thyroid tissue was minced into small pieces and washed several times in Hank's balanced salt solution (HBSS without calcium and magnesium). After digestion with $5 \mathrm{ml}$ collagenase type II and $5 \mathrm{ml}$ dispase solution (Gibco, Eggenstein, Germany) for $2 \mathrm{~h}$ at $37^{\circ} \mathrm{C}$, cells were passed through a $40 \mu \mathrm{m}$ cell strainer and pelleted by centrifugation. Erythrocytes were lysed using $10 \mathrm{ml}$ erythrocyte lysis buffer (Qiagen, Hilden, Germany). The remaining thyrocytes were counted after staining with trypan blue. Nucleated cells from peripheral blood were isolated as described above and also counted. Thyrocytes were diluted as follows: 0/10 $\mathrm{PBMC}$; $1 / 10^{5} \mathrm{PBMC}$; 10/10 $0^{5}$ PBMC; $100 / 10^{5}$ PBMC; 1000/10 $0^{5}$ PBMC. RNA isolation and RT-PCR were performed as described above.

\section{Statistics}

Statistical comparisons were carried out using Sigma-Stat statistical software (Jandel Scientific, Erkrath, Germany) and SPSS software (Chicago, Ilinois, USA). Non-parametric Kruskal-Wallis test was used to compare cancer patients and controls concerning age and gender. Contingency tables were used to assess the association between RT-PCR positivity, age, gender, type of thyroid disease, histological type as well as TNM staging and grading in cancer patients and serum TG levels respectively. Fisher exact test was used to compare the distributions in contingency tables that had 5 or less expected observations in one or more cells. Chi-square analysis was used to compare the distributions in contingency tables that had five or more observations expected in each cell. $P<0.05$ was considered significant. 


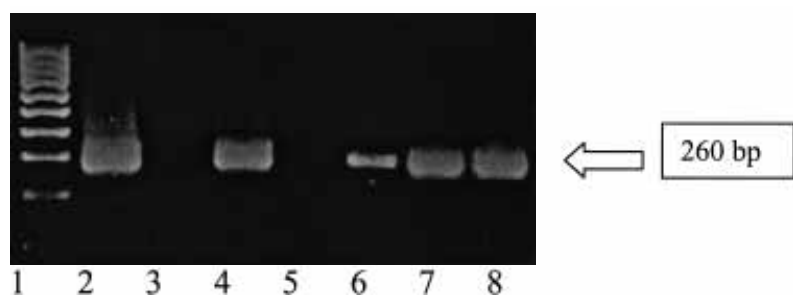

Figure 1 Ethidium bromide-stained agarose gel showing the sensitivity of the RT-PCR assay. Lane 1, $1 \mathrm{~kb}$ ladder (Gibco); lane 2, positive control; lane 3, negative control; lane 4, pure thyroid cells; lane 5, dilution of thyrocytes (TC)/PBMC: $1 / 10^{5}$; lane 6 , dilution of TC/PBMC: $10 / 10^{5}$; lane 7 , dilution of TC/PBMC: 100/105; lane 8, dilution of TC/PBMC: $1000 / 10^{5}$.

\section{Results}

\section{Detection of TPO mRNA in peripheral blood}

After standardisation of nested RT-PGR for detection of thyroid peroxidase mRNA, amplification yielded a 260 base pair fragment as expected. After the first round of RT-PGR no fragments were detectable on the gel. Hybridisation with a non-radioactive oligonucleotide probe and direct nucleotide sequence analysis showed the amplicon's homology with the cDNA sequence of human thyroid peroxidase (Kimura et al. 1989). Nested PGR without prior RT did not show any product of the predicted size.

\section{Thyroid peroxidase RT-PCR assay sensitivity}

Sensitivity was analysed using dilutions of PBMC from a control and thyrocytes obtained from surgery for goitre. By ethidium bromide staining, the expected fragment was still detectable at concentrations of 10 thyrocytes per $10^{5} \mathrm{PBMC}$ (Fig. 1).

\section{Evaluation of RT-PCR assay in cancer patients}

We evaluated 110 patients with a history of thyroid carcinoma but without current metastases (88 papillary, 22 follicular carcinomas) and 10 patients with metastatic disease (4 with papillary cancer, 6 with follicular cancer). Age at initial diagnosis and gender did not have any significant effect on the RT-PCR result. Results of all cancer patients are listed in Table 1.
In our RT-PGR assay, 7 of $10(70 \%)$ patients with metastases were positive for thyroid peroxidase mRNA (3 with papillary, 4 with follicular carcinoma). Of the patients without current metastases 39 of $110(36 \%)$ showed a positive signal (29 of $88(33 \%)$ with papillary carcinoma and 10 of $22(46 \%)$ with follicular carcinoma). There was a significant difference between patients with metastatic disease and cancer patients without current metastases $(P=0 \cdot 04)$.

Of the patients without metastatic disease, significantly more patients with positive lymph nodes $(\mathrm{pN}+)$ at initial diagnosis (10 of $22(45 \cdot 5 \%))$ showed a positive signal in RT-PGR than patients with pN0 (19 of $67(28 \cdot 4 \%))(P=0 \cdot 05)$. RT-PGR results did not show any significant distribution among patients with different tumour size.

Significantly more positive results were found in patients with non-metastatic disease and initial grading G3 (3 of $4(75 \%)$ ) compared with patients with G1 and G2 (18 of $43(41 \cdot 9 \%))(P=0.01)$.

\section{Thyroglobulin measurements in cancer patients}

Serum TG levels were determined in all 120 patients with a history of thyroid carcinoma at the time of RNA extraction. A TG level of more than $5 \mathrm{ng} / \mathrm{ml}$ was considered to be elevated. In 12 patients (10\%) elevated TG levels could be detected (range 16-2028 ng/ml). Nine of the twelve patients $(75 \%)$ were also positive in the RT-PCR, whereas 37 of $108(34 \%)$ patients with normal TG levels were tested positive in the RT-PCR. Three of those 37 patients $(8 \cdot 1 \%)$ had metastatic spread.

Among patients with metastatic disease no significant correlation could be found between RT-PCR results and serum TG measurement. Four of five $(80 \%)$ patients with elevated serum TG were also positive in the RT-PCR and 3 of $5(60 \%)$ patients with normal serum TG were positive in the RT-PCR $(P=0 \cdot 36)$. In patients without metastatic disease the results of both tests showed a positive correlation: 5 of $7(71.4 \%)$ patients with elevated serum TG were positive in the RT-PGR and 69 of $103(67 \%)$ patients with normal serum TG were also negative in the RT-PCR $(P=0 \cdot 0001)$.

Patients with metastases were further analysed: of the 7 RT-PGR-positive patients with metastatic disease, 4 were also positive for TG in the serum. All 4 patients had a progression of the disease 
within the last six months, three suffered from pulmonary metastases detected by CT-scan and one from lymph node metastases in the mediastinum detected by CT-scan.

Of the three patients who were RT-PCRpositive but negative for $\mathrm{TG}$, one had newly discovered pulmonary metastases, which were not detectable in GT-scan but were detectable in PET-scan of the chest. The second patient had pulmonary metastases detectable by CT-scan, the third patient was found to have paratracheal lymph node metastases detected by magnetic resonance imaging.

Of the three patients with metastatic disease but negative RT-PCR results, one had an elevated serum TG level of $91 \cdot 1 \mathrm{ng} / \mathrm{ml}$, a history of two local recurrences which were treated with ${ }^{131} \mathrm{I}$, and pulmonary metastases. The second and third patients were also negative for TG in the blood. One of them had a history of metastatic spread to the spinal cord five years ago, which was treated by ${ }^{131} \mathrm{I}$, but had remained disease-free since then. The other patient had a history of pulmonary metastases, which were treated with ${ }^{131} \mathrm{I}$, but was also disease-free at the time the blood sample was taken.

\section{Evaluation of RT-PCR assay in patients with benign thyroid disease and in controls}

We examined 41 patients with Graves' disease, 44 patients with euthyroid goitre and 54 control patients. Cancer patients and controls were compared concerning age and gender by nonparametric Kruskal-Wallis test, which showed no significant difference between the groups. RT-PCR results were positive in 17 of 41 (41\%) Graves' disease patients, in 15 of $44(34 \%)$ patients with euthyroid goitre and in 4 of $54(7 \cdot 4 \%)$ healthy volunteers.

A significant difference could be detected between patients with thyroid disease - benign as well as malignant - and the control group $(P<0 \cdot 001)$. RT-PGR results did not vary significantly in patients with benign and malignant thyroid disease.

\section{Discussion}

As the presence of distant metastases in patients with differentiated thyroid cancer was found to be an important predictor of outcome, ongoing research is interested in developing new diagnostic methods to detect metastases as early as possible (Carcangui et al. 1985, Brennan et al. 1991, Arturi et al. 1997). To date, the measurement of thyroglobulin in patients' sera and radioiodine scanning are used as standard techniques to monitor thyroid cancer patients after initial treatment. However, these diagnostic methods still have several limitations, for example in cases where serum thyroglobulin is elevated but a radioiodine scan fails to detect metastases (Pineda et al. 1995, Reynolds et al. 1997) or in cases with false-positive ${ }^{131}$ I whole body scans due to inflammation or elimination in body fluids (Brucker-Davis et al. 1996). Even cases with negative serum TG in the absence of antibodies but with clinical disease progression have been reported (Westbury et al. 2000).

Over the last decade, molecular biology based techniques like RT-PGR have been successfully used to detect circulating tumour cells and micro-metastases, for example in patients with cancer of the breast or prostate (Datta et al. 1994, Ghossein \& Rosai 1996). Concerning thyroid carcinoma, several studies have been published investigating thyroid autoantigens as possible molecular markers (Ditkoff et al. 1996, Arturi et al. 1997, Aust et al. 1998, Ringel et al. 1998, 1999, Tallini et al. 1998, Wingo et al. 1999, Biscolla et al. 2000, Bojunga et al. 2000, Bellantone et al. 2001, Fenton et al. 2001, Takano et al. 2001, Savagner et al. 2002). Almost all of them focused, more or less, on the detection of mRNA for thyroglobulin, except Tallini et al. (1998), who also investigated the use of TPO-RT-PGR to detect circulating thyroid cells in the peripheral blood stream of patients with a history of papillary thyroid cancer.

In contrast to Tallini et al. (1998), we also examined patients with follicular thyroid carcinoma, Graves' disease and a large control group. A significant difference in positivity for TPO mRNA expression was found in patients with metastatic thyroid cancer $(70 \%)$ and non-metastatic disease $(36 \%)$ compared with healthy volunteers $(7 \cdot 4 \%)$. One would expect to find all patients with metastases positive in our assay. In agreement with our observations, Tallini et al. (1998) reported 9 cases of patients with distant metastases and found only 5 patients $(55 \%)$ positive for TPO transcripts. In another study only 1 of $5(20 \%)$ patients with metastases was tested positive for TG mRNA 
(Bellantone et al. 2001). Possible explanations for the lack of detectable transcripts could be dedifferentiation with consecutive loss of tissuespecific mRNA expression and also intermittent shedding of tumour cells into the blood stream. The mRNA expression of thyroid autoantigens is significantly lower in malignant compared with normal tissue (Lazar et al. 1999, DeMicco et al. 2000). Brabant and colleagues were able to show that expression of thyroglobulin mRNA as well as TPO mRNA detected by Northern blot is completely lost in anaplastic thyroid cancer tissue (Brabant et al. 1991). Another group found that thyroid cancer tissues from patients with advanced stages express less TPO mRNA compared with those from patients with less advanced stages (Lazar et al. 1999).

Interestingly, we were able to show a significantly higher rate of RT-PCR positivity in patients with G3 at initial diagnosis compared with patients with G1 and G2 among all patients without metastatic disease. Only one study showed that TPO mRNA expression did not seem to be influenced by the grading, whereas mRNA expression of other thyroid antigens correlated in a reciprocal fashion with cancer tissue differentiation (Ohta et al. 1991). However, due to the small number of patients with G3 in our study, these results have to be interpreted cautiously.

A reason for positive results in the group of controls could be a nonspecific low level expression of TPO mRNA by non-thyroid cells. This, so called, illegitimate transcription has been reported by other authors. Aust and co-workers (1998) found TPO transcripts in muscle tissue and dermal fibroblasts. Illegitimate transcription seems to be a more economic option for a cell compared with trying to silence completely the transcription of genes specific for other tissues (Cooper et al. 1994). Another possible cause for positive assay results in controls was introduced by Ringel et al. (1998, 1999) who identified cells from the peripheral blood of healthy individuals as circulating thyroid cells by staining with antithyroglobulin antibodies after magnetic cell sorting. Furthermore, the mRNA-expression of TPO - among other thyroid related antigens - was found in the human thymus (Spitzweg et al. 1999). The authors speculated that this expression might be used to create selftolerance against thyroid antigens during the maturation process of T-lymphocytes.
Of the patients with non-metastatic disease, those with an elevated serum TG level were found to be positive $(71.4 \%)$ in the TPO-RT-PGR more often than patients with normal serum TG levels $(33.0 \%)$. To our knowledge there is currently no other study comparing TPO-RT-PCR and serum TG measurement. Two studies compared results of TG-RT-PGR with serum TG levels and found TG-RT-PGR to be the more sensitive method for the detection of metastases (Biscolla et al. 2000, Savagner et al. 2002). Among our patients tested negative for serum TG mRNA but positive for TPO mRNA, 7 were found to have remaining thyroid tissue in ${ }^{131} \mathrm{I}$ whole body scans, 2 had enlarged lymph nodes in the ultrasound examination of the neck and 2 showed lesions in their ${ }^{131}$ I whole body scans suspicious for pulmonary metastases. In contrast to the two studies mentioned above, other authors found TG mRNA in the blood of patients with papillary cancer only, thus limiting its sensitivity and use as a diagnostic marker - like serum TG - for all thyroid cancer patients (Bellantone et al. 2001). Another study using quantitative TG-RT-PCR tested almost all patients positive, even those with medullary thyroid cancer, and found no statistical correlation between PCR results and patient subgroups or TG levels measured in the serum (Takano et al. 2001). The authors question the method of RT-PCR in peripheral blood as a diagnostic tool in general.

To date, there are some studies concerning the use of TG-RT-PGR for monitoring of thyroid cancer patients. Results range from very promising to disastrous. In our opinion, it might be too early to speculate about the usefulness as results of RT-PGR can be influenced by many factors and no international standard for the detection of mRNA of thyroid antigens in blood has been established yet. RT-PCR cannot replace standard techniques and its role in the diagnostic workup for patients with differentiated thyroid cancer still has to be defined.

In our study, we were able to show a significant difference in TPO-RT-PGR assay comparing patients with metastatic thyroid cancer and patients with non-metastatic disease. Frequency of RTPCR positivity differed significantly when patients with malignant and benign thyroid disease were compared with the group of healthy volunteers. No significant difference in positivity was found 
comparing all subgroups, benign and malignant, of thyroid disease.

In contrast to our results, Tallini et al. (1998) detected a significant difference between malignant and non-malignant thyroid disease but no difference between patients with and without metastases. Tallini and co-workers did not include patients with autoimmune disease in their study. One has to take into account that the ongoing process of inflammation in Graves' disease leads to stimulation of hormone production and growth of the thyroid (Weetman \& McGregor 1994, Berg 1997). Assuming that growth stimulating effects together with massive inflammation may lead to shedding of cells into the peripheral blood, this may be a possible explanation for the high percentage of patients tested positive in RT-PGR among the group of patients with autoimmune thyroid disease.

In conclusion, our data represent the largest study investigating RT-PGR for TPO mRNA transcripts in peripheral blood of patients with malignant and benign thyroid disease. We are able to show that a positive assay correlates significantly with the diagnosis of thyroid disease. Furthermore, we showed for the first time, that patients with metastatic thyroid carcinoma are significantly more often positive in the TPO-RT-PGR assay than patients with non-metastatic disease. In patients with non-metastatic disease, TPO-RT-PCR results correlated significantly with lymph node status and grading as well as with serum TG measurement. However, results have to be interpreted very cautiously. Follow-up studies are neccessary to clarify if cancer patients with non-metastatic disease who were tested positive in TPO-RT-PCR will have a higher rate of local recurrence or metastatic disease.

\section{References}

Akslen LA 1993 Prognostic importance of histologic grading in papillary thyroid carcinoma. Cancer 72 2680-2685.

Arturi F, Russo D, Giuffrida D, Ippolito A, Perrotti N, Vigneri R \& Filetti S 1997 Early diagnosis by genetic analysis of differentiated thyroid cancer metastasis in small lymph nodes. Fournal of Clinical Endocrinology and Metabolism 82 1638-1641.

Aust G, Crisp M, Bosenberg E, Ludgate M, Weetman AP \& Paschke R 1998 Transcription of thyroid autoantigens in nonexpressing tissues. Experimental and Clinical Endocrinology and Diabetes 106 319-323

Bellantone R, Lombardi CP, Bossola M, Ferrante A, Princi P, Boscherini M, Maussier L, Salvatori M, Rufini V, Reale F, Romano L, Tallini G, Zelano G \& Pontecorvi A 2001 Validity of thyroglobulin mRNA assay in peripheral blood of postoperative thyroid carcinoma patients in predicting tumor recurrences varies according to the histologic type: results of a prospective study. Cancer 92 2273-2279.

Berg JP 1997 Autocrine and paracrine cell death in Hashimoto's thyroiditis. European Fournal of Endocrinology 137 122-123.

Biscolla RP, Cerutti JM \& Maciel RM 2000 Detection of recurrent thyroid cancer by sensitive nested reverse transcription-polymerase chain reaction of thyroglobulin and sodium/iodide symporter messenger ribonucleic acid transcripts in peripheral blood. Fournal of Clinical Endocrinology and Metabolism 85 3623-3627.

Bojunga J, Roddiger S, Stanisch M, Kusterer K, Kurek R, Renneberg H, Adams S, Lindhorst E, Usadel KH \& SchummDraeger PM 2000 Molecular detection of thyroglobulin mRNA transcripts in peripheral blood of patients with thyroid disease by RT-PGR British Fournal of Cancer 82 1650-1655.

Brabant G, Maenhaut G, Kohrle J, Scheumann G, Dralle H, Hoang-Vu C, Hesch RD, von zur Muhlen A, Vassart G \& Dumont JE 1991 Human thyrotropin receptor gene: expression in thyroid tumors and correlation to markers of thyroid differentiation and dedifferentiation. Molecular and Cellular Endocrinology 82 R7-R12.

Brennan MD, Bergstralh EJ, van Heerden JA \& McGonahey WM 1991 Follicular thyroid cancer treated at the Mayo Clinic 1946-1970: initial manifestations, pathologic findings and outcome. Mayo Clinic Proceedings 66 11-22.

Brucker-Davis F, Reynolds JC, Skarulis MC, Fraker DL, Alexander HR, Weintraub BD \& Robbins J 1996 False-positive iodine-131 whole body scans due to cholecystitis and sebaceous cyst. Foumal of Nuclear Medicine 37 1690-1693.

Carcangui ML, Zampi G, Pupi A, Castagnoli A \& Rosai J 1985 Papillary carcinoma of the thyroid: a clinicopathological study of 241 cases treated at the University of Florence, Italy. Cancer $\mathbf{5 5}$ 805-828.

Cooper DN, Berg LP, Kakkar G \& Reiss J 1994 Ectopic transcription: new possibilities for the analysis and diagnosis of human genetic disease. Annals of Medicine 26 9-14.

Corey E \& Corey J 1998 Detection of disseminated prostate cells by reverse transcription polymerase chain reaction (RT-PCR): technical and clinical aspects. International fournal of Cancer $\mathbf{7 7}$ 655-673.

Datta YH, Adams PT, Drobyski WR, Ethier SP, Terry VH \& Roth MS 1994 Sensitive detection of occult breast cancer by the reverse-transcriptase polymerase chain reaction. Fournal of Clinical Oncology 12 475-482.

DeMicco G, Kopp F, Vassko V \& Grino M 2000 In situ hybridisation and immunohistochemistry study of thyroid peroxidase expression in thyroid tumors. Thyroid 10 109-115.

Ditkoff BA, Marvin MR, Yemul S, Shi YJ, Chabot J, Feind C \& Lo Gerfo PL 1996 Detection of circulating thyroid cells in peripheral blood. Surgery 120 959-965.

Fenton C, Anderson JS, Patel AD, Lukes Y, Solomon B, Tuttle RM, Ringel MD \& Francis GL 2001 Thyroglobulin messenger ribonucleic acid levels in the peripheral blood of children with benign and malignant thyroid disease. Pediatric Research $\mathbf{4 9}$ 429-434.

Ghossein RA \& Rosai J 1996 Polymerase chain reaction in the detection of micrometastases and circulating tumor cells. Cancer $\mathbf{7 8}$ $10-16$.

Haber RS 1998 Editorial: The diagnosis of recurrent thyroid cancera new approach.. Fournal of Clinical Endocrinology and Metabolism $\mathbf{8 3}$ $4189-4199$.

Kimura S, Hong YS, Kotani T, Ohtaki S \& Kikkawa F 1989 Structure of the human thyroid peroxidase gene: comparison and relationship to the human myeloperoxidase gene. Biochemistry $\mathbf{2 8}$ $4481-4489$

Komeda T, Fukuda Y, Sando T, Kita R, Furukawa M, Nishida N, Amenomori M \& Nakao K 1995 Sensitive detection of circulating 
hepatocellular carcinoma cells in peripheral venous blood. Cancer $752214-2219$.

Ladenson PW, Braverman LE, Mazzaferri EL, Brucker-Davis F, Cooper DS, Garber JR, Wondisford FE, Davies TF, DeGroot LJ, Daniels GH, Ross DS \& Weintraub BD 1997 Comparison of recombinant human thyrotropin administration to thyroid hormone withdrawal for radioactive iodine scanning in patients with thyroid carcinoma. New England Fournal of Medicine 337 888-896.

Lazar V, Bidart JM, Caillou B, Mahe C, Lacroix L, Filetti S \& Schlumberger M 1999 Expression of the Na symporter gene in human thyroid tumors: a comparison study with other thyroidspecific genes. Fournal of Clinical Endocrinology and Metabolism 84 3228-3234.

Ligabue A, Poggioli MC \& Zacchini A 1993 Interference of specific autoantibodies in the assessment of serum thyroglobulin. Fournal of Nuclear Biology and Medicine 37 273-279.

Ohta K, Endo T \& Onaya T 1991 The mRNA levels of thyrotropin receptor, thyroglobulin and thyroid peroxidase in neoplastic human thyroid tissues. Biochemical and Biophysical Research Communications 174 1148-1153.

Pacini F, Agate L, Elisei R, Capezzone M, Ceccarelli C, Lippi F, Moro C \& Pinchera A 2001 Outcome of differentiated thyroid cancer with detectable serum tg and negative diagnostic (131)I whole body scan: comparison of patients treated with high (131)I activities versus untreated patients. Fournal of Clinical Endocrinology and Metabolism 86 4092-4097.

Pineda JD, Lee T, Ain K, Reynolds JC \& Robbins J 1995 Iodine-131 therapy for thyroid cancer patients with elevated thyroglobulin and negative diagnostic scan. Fournal of Clinical Endocrinology and Metabolism 80 1485-1487.

Renneberg H, Friedetzky A, Konrad L, Kurek R, Weingartner K, Wennemuth G, Tunn UW \& Aumuller G 1999 Prostate specific membrane antigen (PSM) is expressed in various human tissues: implication for the use of PSM reverse transcription polymerase chain reaction to detect hematogenous prostate cancer spread. Urology Research 27 23-27.

Ringel MD, Ladenson PW \& Levine MA 1998 Molecular diagnosis of residual and recurrent thyroid cancer by amplification of thyroglobulin messenger ribonucleic acid and peripheral blood. Journal of Clinical Endocrinology and Metabolism 83 4435-4442.

Ringel MD, Balducci-Silano PL, Anderson JS, Spencer CA, Silverman J, Sparling YH, Francis GL, Burman KD, Wartofsky L, Ladenson PW, Levine MA \& Tuttle RM 1999 Quantitative reverse transcription-polymerase chain reaction of circulating thyroglobulin messenger ribonucleic acid for monitoring patients with thyroid carcinoma. Fournal of Clinical Endocrinology and Metabolism 84 4037-4042.
Reynolds JC \& Robbins J 1997 The changing role of radioiodine in the management of differentiated thyroid cancer. Seminars in Nuclear Medicine 27 152-164.

Savagner F, Rodien P, Reynier P, Rohmer V, Birgorgne JC \& Malthiery Y 2002 Analysis of Tg transcripts by real-time RT-PCR in the blood of thyroid patients. Fournal of Clinical Endocrinology and Metabolism 87 635-639.

Simpson WJ, McKinney SE, Carruthers JS, Gospodarowicz MK, Sutcliffe SB \& Panzarella T 1987 Papillary and follicular thyroid cancer - prognostic factors in 1578 patients. American Fournal of Medicine 83 479-488.

Sobin LH \& Fleming ID 1997 TNM Classification of Malignant Tumours, 5th edition. Union Internationale Contre le Cancer and the American Joint Committee on Cancer. Cancer 80 1803-1804.

Spencer CA, Takeuchi M, Kazarosyan M, Wang CC, Guttler RB, Singer PA, Fatemi S, LoPresti JS \& Nicoloff JT 1998 Serum thyroglobulin autoantibodies: prevalence, influence on serum thyroglobulin measurement, and prognostic significance in patients with differentiated thyroid carcinoma. Fournal of Clinical Endocrinology and Metabolism 83 1121-1127.

Spitzweg C, Joba W \& Heufelder AE 1999 Expression of thyroidrelated genes in human thymus. Thyroid $\mathbf{9}$ 133-141.

Takano T, Miyauchi A, Yoshida H, Hasegawa Y, Kuma K \& Amino N 2001 Quantitavie measurement of thyroglobulin mRNA in peripheral blood of patients after total thyroidectomy. British Fournal of Cancer 85 102-106.

Tallini G, Ghossein RA, Emanuel J, Gill J, Kinder B, Dimich AB, Costa J, Robbins R, Burrow GN \& Rosai J 1998 Detection of thyroglobulin, thyroid peroxidase and ret/ptcl mRNA transcripts in the peripheral blood of patients with thyroid disease. Fournal of Clinical Oncology 82 1158-1166.

Wasserman L, Dreilinger A, Easter D \& Wallace A 1999 A seminested RT-PCR assay for her2/neu: initial validation of a new method for the detection of disseminated breast cancer. Molecular Diagnosis 4 21-28.

Weetman AP \& McGregor AM 1994 Autoimmune thyroid disease: further developments in our understanding. Endocrine Reviewes 15 788-830.

Westbury C, Vini L, Fisher C \& Harmer C 2000 Recurrent differentiated thyroid cancer without elevation of serum thyroglobulin. Thyroid $\mathbf{1 0} 171-176$.

Wingo ST, Ringel MD \& Anderson JS 1999 Quantitative reverse transcription-PCR measurements of thyroglobulin mRNA in peripheral blood of healthy subjects. Clinical Chemistry 45 785-789.

Received in final form 29 July 2002 Accepted 31 July 2002 